\title{
CHEMICAL VAPOUR INFILTRATION (CVI) OF SILICON CARBIDE FIBRE PREFORMS
}

\author{
R. LUNDBERG* ${ }^{*}$ L. PEJRYD ${ }^{*}$ and G. LÖÖF* \\ "Volvo Flygmotor $A B$, Aerospace Division, S-461 81 Trollhättan, \\ Sweden \\ ** Tixon $A B, V a l l a$ Industriområde, S-583 47 Linköping, Sweden
}

\begin{abstract}
An alternative fabrication technique is proposed for ceramic matrix / ceramic fibre composites involving filling a fibre fabric preform with a $\mathrm{Si}_{2} / \mathrm{Si}_{3} \mathrm{~N}_{4}$ slurry and subsequently reaction bonding. For the first processing step in this process, chemical vapour infiltration (CVI) was evaluated as a means of both binding together and protecting the fibres. SiC (Nicalon) fibre preforms consisting of through-stitched 2D fabrics were infiltrated. The preform thickness was more than $4 \mathrm{~mm}$ and a $3 \mu \mathrm{m}$ TiC/TiN layer was subsequently deposited on all the fibres, even in the centre of the preform after less than $8 \mathrm{~h}$. The purpose of the CVI layer was firstly to bind the fibres together, but also to protect the fibre/matrix interfacial carbon film from reaction with the subsequently infiltrated matrix. The remaining porosity of the preform was filled with a $\mathrm{Si} / \mathrm{Si}_{3} \mathrm{~N}_{4}$ powder slurry which was nitrided to form a reaction bonded $\mathrm{Si}_{3} \mathrm{~N}_{4}$ (RBSN) matrix. The advantage of this combined CVI/RBSN route is a substantial cut in processing time compared to a process where most of the porosity is filled using CVI.
\end{abstract}

\section{1.- Introduction}

Ceramic composite materials are becoming more and more interesting for aerospace applications where low density, good oxidation and corrosion resistance and high strength at temperatures above $1000^{\circ} \mathrm{C}$ are required (1-4).

The general principle of long fibre reinforcement of ceramics is not so much to reinforce, i.e. to strengthen or stiffen (which is the case for polymer or metal matrix composites), but rather to overcome poor reliability and brittleness of ceramic materials by creating a "graceful" fracture due to energy absorbing, crack growth controlling mechanisms (5). These mechanisms can only operate if the fibre/matrix bond strength is sufficiently low in relation to fibre strength to prevent cracks from propagating through the fibres and to result in a fracture behaviour where the fibres remain undamaged in spite of multiple matrix cracking. The currently most usual method of obtaining a weak fibre/matrix interface is to deposit a thin coating of a low shear strength material such as boron nitride or graphite on the fibres. Unfortunately both $\mathrm{BN}$ and $\mathrm{C}$ are readily oxidised at temperatures well below $1000^{\circ} \mathrm{C}$ as well as being fairly reactive towards many ceramic matrix materials at the processing temperature.

A class of ceramic composites manufactured by the chemical vapour infiltration (CVI) of three-dimensionally woven fibre preforms (see Figure 1.) have been developed, mainly in France (6,7). SiC (Nicalon) fibres in a CVI-SiC matrix are currently being evaluated as a potential aeroengine material. In this material the pure $\mathrm{SiC}$ matrix protects the fibre/matrix interface from oxidation during use. To build up the entire matrix by CVI is a tedious process in which $\mathrm{SiC}$ is deposited at a low deposition rate inside the pore structure of a 
fibre preform. When the surface pores become closed, the partly infiltrated preform is taken out of the reactor and diamond ground in order to open up the surface. This process requires processing times of the order of weeks to months and is consequently fairly costly. The resulting mechanical properties at high temperatures and in oxidising environments of the composites are, however, excellent.

The aim of the present work has been to develop a production method for ceramic composites, avoiding time consuming CVI and using fairly low cost matrix materials, while still obtaining adequate high temperature properties. The general approach was to use CVI only for the first matrix infiltration, in order to obtain a protective ceramic coating on the thin carbon layer already present on the fibre surface. The remaining porosity in the preform was filled using a previously developed method (8-11) involving $\mathrm{Si}(\mathrm{s}) / \mathrm{Si}_{3} \mathrm{~N}_{4}(\mathrm{~s})$ slurry infiltration and reaction with $\mathrm{N}_{2}$ (g) (nitridation) to form a reaction bonded $\mathrm{Si}_{3} \mathrm{~N}_{4}$ (RBSN) matrix.
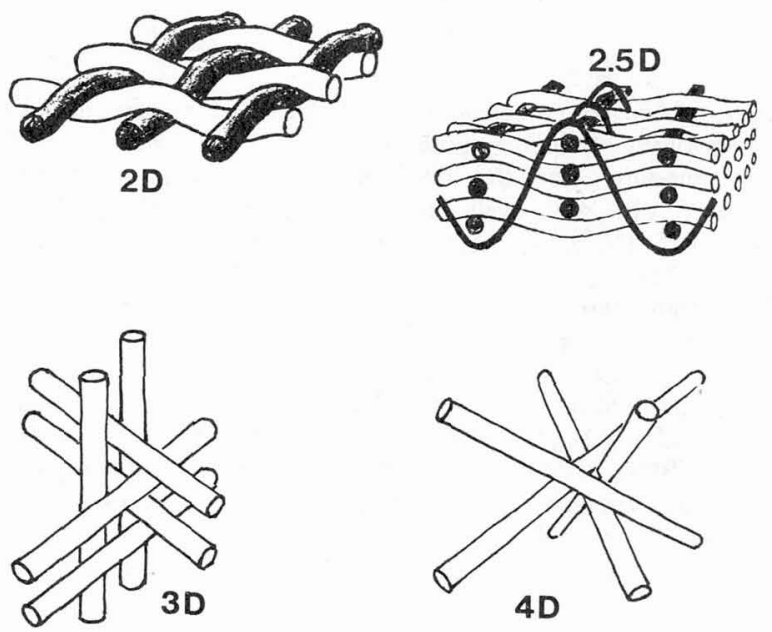

Figure 1. Some examples of 3-dimensionally woven fibre preforms.

TiC/TiN was chosen as fibre coating on the basis of thermodynamic computer-aided calculations (12) which showed that silicon forms $\mathrm{Si}_{3} \mathrm{~N}_{4}$ in $\mathrm{N}_{2}$ rather than reacting with TiN (see Table 1.), and that $\mathrm{TiC}$ is inert towards carbon and SiC. "Furthermore, to use a Ti-based rather than a si-based coating makes it more straightforward to use a standard CVD equipment as used by the cemented carbide industry.

Table 1. Calculated equilibrium compositions in the TiN/Si-system at $\mathbf{P}=1$ atm (12).

1. NITROGEN ATMOSPHERE

Reactants (moles): $1 \mathrm{TiN}(\mathrm{s}), 3 \mathrm{Si}(\mathrm{s})$ and $10 \quad \mathrm{~N}_{2}$ (g).

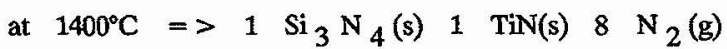

2. ARGON ATMOSPERE

Reactants (moles): $1 \mathrm{TiN}(\mathrm{s}), \quad 3 \mathrm{Si}(\mathrm{s})$ and $1 \operatorname{Ar}(\mathrm{g})$

at $1400^{\circ} \mathrm{C}=>\quad 3 \quad \mathrm{Si}(\mathrm{s}), \quad 1 \quad \operatorname{TiN}(\mathrm{s}), \quad 0.001 \quad \mathrm{TiSi}(\mathrm{s}), \quad 1 \quad \operatorname{Ar}(\mathrm{g})$ 
Several investigations have shown that it is possible to deposit various ceramic coatings on ceramic monofilaments, ceramic fibre tow, or single fabrics in a laboratory scale reactor $(13,14)$. Little has however been reported on process parameters for full scale CVI of larger components. In the present investigation the possibility of performing chemical vapour infiltration using a production scale reactor was therefore evaluated.

\section{2.- Experimental}

Orthogonal eight harness satin weaves of SiC fibres (Nicalon NL 607, C-coated grade, Nippon Carbon Ltd, Japan, fibre mean diameter $15 \mu \mathrm{m}$ ) were stitched together using more flexible lower diameter $(10 \mu \mathrm{m})$ Si-Ti-C-O fibres (Tyranno, UBE Industries, Japan). In this way two-directional through-stitched stacked fabric preforms of more than $4 \mathrm{~mm}$ thickness were produced. The priciple of the fibre architecture is close to the $2.5 \mathrm{D}$ preform shown in Figure 1 . The $\mathrm{SiC}$ fibres were supplied by the manufacturer with a thin carbon surface coating to ensure a low fibre/matrix bond strength in ceramic systems.

The CVI was performed at Tixon $A B$ in a production scale CVD reactor (250 Tandem, Berna Ltd, Schweiz) with a cylindrical shape $\left(225 / 750 \mathrm{~mm}\right.$ inner diameter/height). $\mathrm{TiCl}_{4}$, $\mathrm{H}_{2}$ and $\mathrm{CH}_{4}$ at $80 \mathrm{mbar}, 1040^{\circ} \mathrm{C}$ for $2.25 \mathrm{~h}$ were used for the TiC layer and $\mathrm{TiCl}_{4}$, $\mathrm{H}_{2}, \mathrm{~N}_{2}$ and $\mathrm{HCl}$ at $400 \mathrm{mbar}, 950^{\circ} \mathrm{C}$ for $2.75 \mathrm{~h}$ yielded the TiN.

The $\mathrm{Si} \mathrm{Si}_{3} \mathrm{~N}_{4}$ slurry infiltration and subsequent nitridation methods have been reported elsewhere (8-11).

\section{3.- Results and Discussion}

As can be seen in Figure 2 it was possible to infiltrate the fibre preform to its centre and deposit a TiC/TiN layer on the SiC fibres. The process conditions used were not very different from the conditions used for CVD coating of non-porous material. These conditions could be used since only a fairly thin ceramic layer was desired. If a high proportion of the porosity is to be filled using CVI more care must be taken in optimising the deposition rate so as to obtain a higher deposition rate at the centre of the fibre preform than at the surface $(15,16)$. The $3 \mu \mathrm{m}$ ceramic layer provided rigidity to the flexible preform so that no support was needed during the subsequent slurry infiltration. Figure 3 shows the fully infiltrated $\mathrm{SiC} /(\mathrm{TiC} / \mathrm{TiN}-\mathrm{CVI}) / \mathrm{RBSN}$ composite material after nitriding. As predicted the TiC/TiN-layer has not reacted, neither with the SiC fibres during $\mathrm{CVI}$ nor with the silicon during the reaction bonding step.

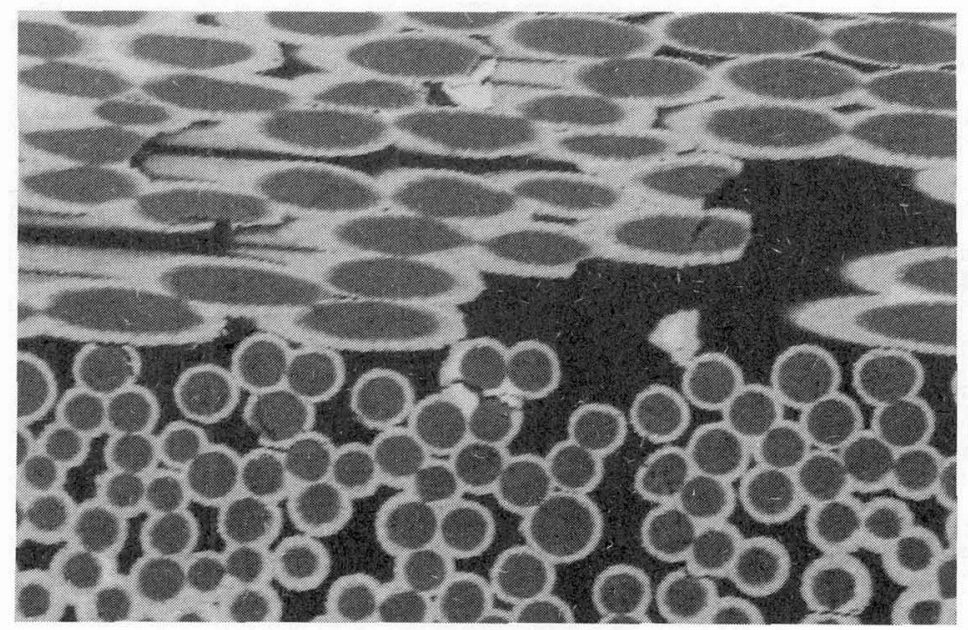

Figure 2. SEM micograph of TiC/TíN-infiltrated SiC-fibre preform. From the centre of a $4 \mathrm{~mm}$ thick piece.

(Back-scattered electron image. Fibre diameter $15 \mu \mathrm{m}$ ) 


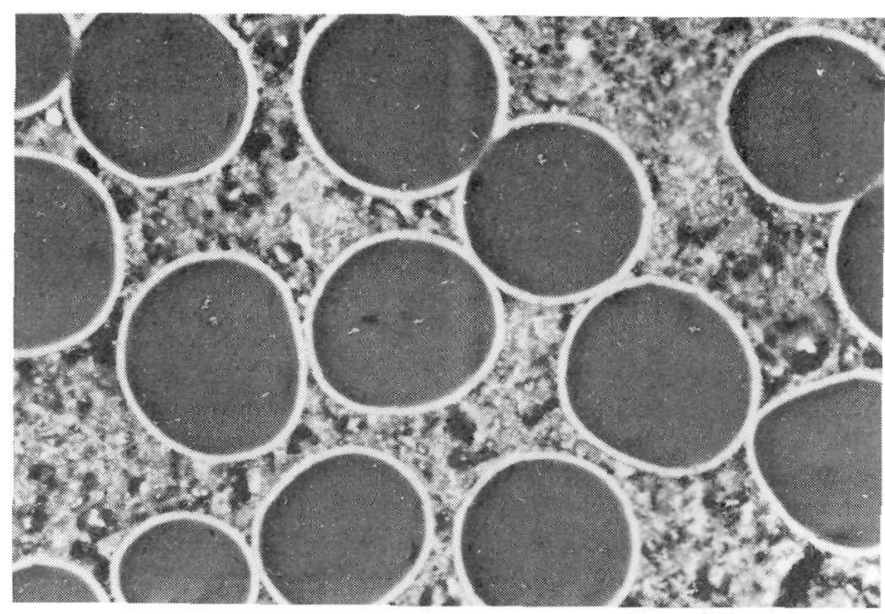

Figure 3. SEM micrograph showing the final microstructure of a $\mathrm{SiC} /(\mathrm{TiC} / \mathrm{TiN}-\mathrm{CVI}) / \mathrm{RBSN}$ ceramic composite.

(Back scattered electron image. Fibre diameter $15 \mu \mathrm{m}$ )

\section{4.- Conclusions}

It can be concluded that CVI of fibre preforms can be performed in commercially available standard CVD reactors without any major changes of either reactor design or process parameters. This is true at least for limited thickness depositions having the function of providing a protective fibre coating at the same time as binding the fibres together giving a rigid preform with enough strength for the subsequent slurry infiltration. A combined CVI/slurry infiltration process offers considerable potential savings of cost and time as compared to a pure CVI process. Using $\mathrm{CVI}$ of a preform for the fibre coating step rather than CVD-coating of individual fibres or strands prior to preform production also makes the manufacturing process more straigthforward.

\section{5.- Acknowledgements}

Dr. Richard Warren is sincerely thanked for sharing his profound knowledge of composite materials and the English language.

\section{6.- References}

11 LAMICQ, P., "Ceramic Matrix Composites - A New Concept for New Challenges", Proc. Int. Conf. High Temperature Materials for Power Engineering, Kluwer Academic Publishers, Brussels (1990) 1559-1574

12/ PHILLIPS, D.C.,"High Temperature Fibre Composites" Proc.Int.Conf. ECCM-2/ICCM-VI, Elsevier Publ., vol 2, (1987) 2.1-2.32

13/ Special issue on ceramic matrix composites, Composites Science and Technology 37 (1990)

14/ Special issue on ceramic matrix composites, Am. Ceram. Soc. Bull. 68 (2) (1989) 
15/ DAVIDGE, R.W,"The Mechanical Properties and Fracture Behaviour of Ceramic-Matrix Composites (CMC) Reinforced With Continuous Fibres" and WARREN, R., SARIN, V.K.,"Fracture of Whisker Reinforced Ceramics", Chapters 13 and 14 in: Application of Fracture Mechanics to Composite Materials, Elsevier Publ., Ed. Friedrich K., (1989) $\quad 547-614$

16/ CRISTIN, F., NASLAIN, R., BERNARD, C.,"A Thermodynamic and Experimental Approach of SiC CVD, Application to the CVD-Infiltration of Porous Carbon Composites", Proc. 7th Int. Conf. CVD, Ed. Sedwick, T.O.,\& Lydin, H., Electrochem. Soc., Princeton, USA, (1979) 449

I7/ LAMICQ, P.J., BERNHART, G.A., DAUCHIER, M.M., MACE, J.G., "SiC/SiC Composite Ceramics", Am. Ceram. Soc. Bull. 65 (2) (1986) 336-338

/8/ LUNDBERG, R., POMPE, R., CARLSSON, R., GOURSAT, P., "Fibre Reinforced Silicon Nitride Composites", Composites Science and Technology 37 (1990) 165-176

19/ BRANDT, J., RUNDGREN, K., POMPE, R., LUNDBERG, R., PEJRYD, L., "Development of Silicon Nitride Based Matrices", Proc. Int. Conf. Ceramic Materials and Components for Engines, Göteborg, Sweden, june 10-12 (1991) to be published

/10/ SWAN, H., O'MEARA, C., BRANDT, J. RUNDGREN, K., POMPE, R., "Development of $\mathrm{SiC}$ Fibre Reinforced Silicon Nitride", Proc. Int. Conf. ECerS-2, Augsburg, Germany, sept. 11-14 (1991) to be published

111 POMPE, R., HERMANSSON, L., CARLSSON, R., "Development of Commersially Advantageous Techniques for Fabrication of Low Shrinkage $\mathrm{Si}_{3} \mathrm{~N}_{4}$-based Materials", Sprechsaal 115 (1982) 1098-1101

112/ Ekvicalc 1.21, Serial \# 140902691-054, Svensk EnergiData, Agersta, S-74022 Balinge, Sweden

13/ GULDEN, T.D., HAZLEBECK, D.A., NORTON, K.P., STRECKERT, H.H., "Ceramic Fibre Coating by Gas-Phase and Liquid-Phase Processes", Ceram. Eng. Sci. Proc. 11 (9-10) (1990) $\quad 1539-1553$

14/ SHERMAN, A.J., TUFFIAS, R. H., "Composite Reinforcements Via Chemical Vapour Deposition", Ceram. Eng. Sci. Proc. 11 (9-10) (1990) 1500-1511

15/ CURRIER; R.P., "Overlap Model for Chemical Vapour Infiltration of Fibrous Yarns", J. Am. Ceram. Soc. 73 (8) (1990) 2274-2280

16/ NASLAIN, R., LANGLAIS, F., ROSSIGNOL, J.Y., HANNACHE, H., QUENISSET, J.M., "Ceramic-Ceramic Composite Materials Obtained According to the CVI Route", Proc. Int. Conf. ECCM-1, Bordeaux, France (1985) 